\title{
Análise ambiental de empreendimentos dos catadores de materiais recicláveis em rede, Campina Grande, Paraíba, Brasil
}

Os catadores de materiais recicláveis promovem o retorno da matéria prima ao setor produtivo, buscando na coleta seletiva um modo de aquisição de trabalho e renda, ao passo que contribuem para gestão ambiental, impedindo que os materiais recicláveis sejam descartados erroneamente ou aterrados. $\mathrm{O}$ objetivo deste trabalho foi analisar sob a ótica ambiental os benefícios da coleta seletiva de resíduos sólidos urbanos realizada pelos empreendimentos de catadores de materiais recicláveis. Trata-se de uma pesquisa qualitativa que envolveu cinco empreendimentos de catadores de materiais recicláveis que atuam na cidade de Campina Grande (100\%), estado da Paraíba. A pesquisa ocorreu de 2018 a 2019. Durante o estudo, constatou-se a média mensal de recuperação de 51 toneladas de papel e papelão, 11,2 toneladas de plástico, 3,8 toneladas de metal, 0,17 toneladas de vidro e 0,61 toneladas de outros materiais, perfazendo a média mensal de aproximadamente 67 toneladas de materiais recicláveis destinada ao mercado da reciclagem. Consequentemente, aponta-se a mitigação de diversos impactos negativos sobre a saúde ambiental e humana, como a redução de impactos oriundos da extração, do transporte e beneficiamento da matéria prima e do uso de combustíveis fósseis empregados como matéria prima na indústria. Foram poupados os recursos naturais água, energia, dentre outros. $\mathrm{O}$ trabalho que os catadores de materiais recicláveis estão desenvolvendo na gestão de resíduos sólidos urbanos, evita sobremodo, a poluição e a contaminação nos sistemas terrestres, aquáticos, atmosféricos, industriais e urbanos, além de gerar emprego e renda.

Palavras-chave: Meio ambiente; Resíduos sólidos; Reciclagem.

\section{Environmental analysis of enterprises for collectors recyclable materials, Campina Grande, Paraíba, Brazil}

\begin{abstract}
The collectors of recyclable materials return the raw material to the productive sector. They seek in selective collection a way of acquiring work and income, and contributing to environmental management, preventing recyclable materials being disposed wrong way. In addition to generating employment and income. The objective of work was to analyze from an environmental perspective the benefits of the selective collection of solid urban waste carried out by recyclable material collectors. It is a qualitative research that involved five enterprises of recyclable material collectors that operate in the city of Campina Grande (100\%), state of Paraíba. The survey took place from 2018 to 2019. During the study, the monthly average recovery was found to be 51.08 tons of paper and cardboard, 11.2 tons of plastic, 3.8 tons of metal, 0.17 tons of glass and 0.61 tons of other materials, making a monthly average of 67 tons of recyclable materials destined for the recycling Market. The mitigation of several negative impacts on human and environmental health was observed, such as the reduction of impacts the extraction, transportation and processing of raw materials and the use of fossil fuels used as raw materials in industry. Natural resources water, energy, among others, were spared. The work that recyclable material collectors are carrying out in the management of urban solid waste, avoids over-pollution, pollution and contamination in terrestrial, aquatic, atmospheric, industrial and urban systems, in addition to generating jobs and income.
\end{abstract}

Keywords: Environment; Solid waste; Recycling.

Topic: Desenvolvimento, Sustentabilidade e Meio Ambiente

Reviewed anonymously in the process of blind peer.
Received: $10 / 08 / 2020$ Approved: $21 / 09 / 2020$
Bárbara Daniele Santos (ID)

Universidade Federal de Campina Grande, Brasil

http://lattes.cnpq.br/3443764289287997

http://orcid.org/0000-0003-2298-4250

barbara_031@hotmail.com

Rosires Catão Curi (iD)

Universidade Federal da Paraíba, Brasil

http://lattes.cnpq.br/7625445154639508

http://orcid.org/0000-0001-6924-4204

rosirescuri@yahoo.com.br

Monica Maria Pereira da Silva (id

Universidade Estadual da Paraíba, Brasil

http://lattes.cnpq.br/8972860324282858

http://orcid.org/0000-0001-6924-4204

monicaea@terra.com.br
Referencing this:

SANTOS, B. D.; CURI, R. C.; SILVA, M. M. P.. Análise ambiental de empreendimentos dos catadores de materiais recicláveis em rede, Campina Grande, Paraíba, Brasil. Revista Ibero Americana de Ciências Ambientais, v.11, n.5, p.482-499, 2020. DOI:

http://doi.org/10.6008/CBPC2179-6858.2020.005.0044 


\section{INTRODUÇÃO}

A ascensão da produção de resíduos sólidos urbanos, mais que duplicou nas últimas décadas em todo globo terrestre. Consequência do ritmo de produção e de consumo e da urbanização das cidades. Este crescimento vertiginoso revela um forte impacto negativo sobre os recursos naturais que quando transformados em resíduos são descartados de forma inadequada, degradando os diferentes sistemas ambientais, comprometendo substancialmente a estabilidade ambiental e a saúde humana em curto, médio e longo prazos. A pandemia provocada pelo coronavírus, cujos efeitos adversos são sentidos em todo mundo, exemplifica o cenário de instabilidade ambiental e social.

Diante da problemática proveniente da crescente geração e destinação indevida dos resíduos sólidos, emerge a necessidade de gestão, em decorrência de suas implicações econômicas, sociais, ambientais e sanitárias (SILVA et al., 2019), visando aplicar, sobretudo, formas corretas de tratamento e disposição final dos resíduos sólidos gerados nos municípios, transformando-se problemas em solução, como afirma Silva (2020)

Conforme descreve a literatura (KUHN et al., 2018; REICHERT et al., 2014; ABRAMOVAY et al., 2013) a gestão de resíduos sólidos urbanos compreende um conjunto de regulações e medidas efetivas que visa equacionar os impactos negativos dos resíduos sólidos, principalmente em grandes centros urbanos, direcionando soluções para gerenciar conforme o princípio de sustentabilidade. No Brasil, o instrumento regulatório da gestão de resíduos sólidos é a Política Nacional de Resíduos Sólidos, Lei 12.305/10 (BRASIL, 2010).

Os catadores de materiais recicláveis são considerados os grandes protagonistas da coleta seletiva no Brasil, uma vez que na maioria das cidades brasileiras a coleta seletiva ainda não está institucionalizada (KUNH et al., 2018; SILVA et al., 2019; SANTOS et al., 2017a). Ao realizarem, a coleta dos resíduos sólidos na fonte geradora, os catadores de materiais recicláveis garantem o retorno da matéria prima ao setor produtivo, o mercado da reciclagem, e obtém na comercialização renda para sustentar sua família, ao passo que contribuem para gestão ambiental, impedindo que os resíduos sólidos se transformem em lixo e que sejam aterrados.

O cenário de atuação desses profissionais, porém, ainda remete a insalubridade, exposição a diversos riscos, à ausência de infraestrutura e de equipamentos para execução das atividades e de proteção individual (SILVA et al., 2019; SANTOS et al., 2017b; CASTILHO et al., 2012; SILVA et al., 2012). Alguns estudos descrevem as condições de trabalho e infraestrutura que estão inseridos os catadores de materiais recicláveis de Campina Grande e apontam que esses profissionais estão submetidos a riscos físicos, químicos, biológicos e de acidentes (SILVA et al., 2019; COUTINHO, 2017; SOUZA et al., 2015; MAIA et al., 2013; SILVA et al., 2010), afetando de forma direta a sua qualidade de vida.

As cooperativas e associações de catadores de materiais recicláveis buscam no fortalecimento coletivo desenvolver ações que favoreçam a negociação dos materiais recicláveis, o aumento da competitividade no mercado da reciclagem e a melhoria das condições de trabalho e de vida. São norteados 
pelos princípios da Economia Solidária, autogestão, associativismo e cooperativismo, a fim de se organizar de forma economicamente sustentável ao longo do tempo. Neste sentido, o objetivo deste trabalho foi analisar sob a ótica ambiental os benefícios da coleta seletiva realizada pelos empreendimentos de catadores de materiais recicláveis em Campina Grande, estado da Paraíba, Brasil.

\section{METODOLOGIA}

\section{Característica da pesquisa}

O trabalho foi realizado no período de março de 2018 a dezembro de 2019 na cidade de Campina Grande/PB. A pesquisa caracteriza-se de natureza qualitativa do tipo participante. Assim como descreve Bardin (2009), a pesquisa qualitativa "é válida, sobretudo, na elaboração das deduções específicas sobre um acontecimento ou uma variável de inferência precisa, e não em inferências gerais". Para Thiollent (2007), a pesquisa participante faz parte de um projeto de ação social ou da resolução de problemas coletivos que tem caráter emancipatório.

\section{Características do espaço amostral}

O espaço amostral deste estudo constitui a cidade de Campina Grande, distante a $120 \mathrm{~km}$ da capital do estado da Paraíba, João Pessoa. Situada entre as coordenadas: $7^{\circ} 13^{\prime} 50^{\prime \prime}$ sul, e $35^{\circ} 52^{\prime} 52^{\prime \prime}$ oeste. 0 munícipio tem área territorial de 593, 026 km² e população estimada em 410.332 habitantes (IBGE, 2017). A densidade demográfica de 648,31 hab/ $/ \mathrm{km}^{2}$ (IBGE, 2010). Enquanto o índice de Desenvolvimento Humano Municipal é de 0,72 (IBGE, 2010). A cidade possui taxa de esgotamento sanitário de 84,1\% e urbanização de vias públicas 19,4 \% (IBGE, 2010). Campina Grande é considerada polo em educação, tecnologia e saúde no Estado da Paraíba e na região Nordeste.

\section{Caracterização dos empreendimentos de catadores de materiais recicláveis de Campina Grande- PB}

Este trabalho é parte de uma tese de doutorado que envolve cinco empreendimentos de catadores de materiais recicláveis organizados em cooperativa ou associação. O estudo foi aprovado pelo Comitê de Ética em Pesquisa Envolvendo Seres Humanos (CEP) da Universidade Federal de Campina Grande- UFCG, com o parecer $n^{\circ} 3.683 .070$.

Os empreendimentos que atuam em Campina Grande, estado da Paraíba, Brasil, são: COTRAMARE (Cooperativa dos Trabalhadores de Materiais Recicláveis); CATAMAIS (Cooperativa de Catadores e Catadoras de Materiais Recicláveis); ARENSA (Associação de Catadores de Materiais Recicláveis da Comunidade Nossa Senhora Aparecida), CAVI (Centro de Artes em vidros); CATACAMPINA (Cooperativa de Trabalho dos Catadores e Catadoras de Materiais Recicláveis de Campina Grande). Neste estudo, optou-se por classificar os empreendimentos com letras alfabéticas (A, B, C, D, E), observando a ordem cronológica de formalização dos mesmos. As principais características e a classificação dos empreendimentos estão descritas no quadro 1. 
Quadro 1: Classificação e principais características da organização dos empreendimentos de catadores de materiais recicláveis de Campina Grande, Paraíba, Brasil.

\begin{tabular}{|l|l|l|l|l|}
\hline Classificação & Empreendimento & $\begin{array}{l}\text { Formalização } \\
\text { Ano }\end{array}$ & $\begin{array}{l}\text { Membros } \\
\text { No }\end{array}$ \\
\hline A & COTRAMARE & 2001 & 14 & Cooperativa \\
\hline B & CATAMAIS & 2008 & 14 & Cooperativa \\
\hline C & ARENSA & 2009 & 14 & Associação \\
\hline D & CAVI & 2013 & 7 & Associação \\
\hline E & CATACAMPINA & 2015 & 10 & Cooperativa \\
\hline
\end{tabular}

\section{Etapas e instrumentos de coleta dos dados}

Na primeira etapa desse trabalho foi realizada uma pesquisa exploratória com intuito de conhecer o grupo alvo de estudo. Na segunda etapa, a partir do acompanhamento das atividades dos catadores de materiais recicláveis foi feita a caracterização gravimétrica dos resíduos sólidos coletados, utilizando-se da observação direta e participante. O acompanhamento das atividades ocorreu em dois ciclos, cada ciclo composto por três acompanhamentos semanais, totalizando seis amostras por empreendimento.

Na terceira etapa foram quantificados os recursos naturais poupados a partir das atividades dos catadores de materiais recicláveis. Os valores enunciados na tabela 1 foram utilizados para mensurar a economia de água, energia, bauxita, petróleo e biomassa (árvore) poupados a partir da reciclagem dos materiais: alumínio, papel e plástico.

Tabela 1: Recursos naturais usados na produção de uma tonelada de alumínio, papel e plástico e a respectiva redução desses recursos a partir da reciclagem.

\begin{tabular}{|c|c|c|c|c|c|c|c|c|c|c|}
\hline \multirow[b]{3}{*}{ Produto } & \multicolumn{10}{|c|}{ Recursos Naturais } \\
\hline & \multicolumn{3}{|l|}{ Água (L) } & \multicolumn{3}{|c|}{ Energia (Kwh) } & \multicolumn{4}{|l|}{ Matéria prima } \\
\hline & Usada & Poupada & (\%) & Usada & Poupada & (\%) & Matéria prima & Usada & Poupada & (\%) \\
\hline Alumínio & $*$ & * & * & 17.600 & 16.900 & 96 & Bauxita (t) & 5 & 5 & 100 \\
\hline \multirow[t]{2}{*}{ Papel } & 100.000 & 98.000 & 98 & 4.980 & 3.510 & 70 & Árvore (u) & $*$ & 30 & $*$ \\
\hline & & & & & & & Petróleo (barril) & $*$ & 2,5 & $*$ \\
\hline Plástico & * & * & * & 6.740 & 5.300 & 79 & Petróleo (barril) & * & 6,3 & * \\
\hline
\end{tabular}

Legenda: $t$ (tonelada); u (unidade); *valor não estimado.

Fonte: Ribeiro et al. (2014).

De acordo com Ribeiro et al. (2014), com a reciclagem do papel, poupa-se $98 \%$ da água utilizada na fabricação de uma tonelada do mesmo material. A redução da energia é verificada com os percentuais: $96 \%$ (alumínio), 70\% (papel), 79\% (plástico). Ademais, a utilização da bauxita é reduzida em 100\% com a reciclagem do alumínio. A quantidade de barris ${ }^{1}$ de petróleo economizada é de 2,5 barris na produção do papel e 6,3 barris na produção de plástico. A redução de biomassa (árvore) na produção de uma tonelada de papel, a partir do papel reciclado, chega a 30 unidades. Para calcular a redução dos recursos naturais (água, energia e bauxita) poupados com a reintrodução dos materiais recicláveis recolhidos pelos empreendimentos: alumínio, papel e plástico, utilizou-se a Equação 1:

\section{$Q=Q U \times M R \times P$}

Onde: $\mathbf{Q}=$ quantidade de recurso natural poupada; $\mathbf{Q U}=$ quantidade de recurso natural utilizada na fabricação; $\mathbf{M R =}$ quantidade de material reciclada; $\mathbf{P}=$ percentual de redução na reciclagem.

Para calcular a redução dos recursos naturais (petróleo e árvore) foi empregada a Equação 2:

\footnotetext{
${ }^{1} 1$ barril corresponde a aproximadamente 159 litros de petróleo (PEREIRA et al. 2018). 


\section{$Q=M R \times Q P$}

Eq (2)

Onde: $\mathbf{Q}=$ quantidade de recurso natural poupada; $\mathbf{M R}=$ quantidade de material reciclada; $\mathbf{Q P}=$ quantidade de matéria prima poupada.

\section{Análise dos dados}

Os dados obtidos foram analisados de forma qualitativa e quantitativa. Posteriormente, na quarta e última etapa, os dados foram interpretados e discutidos com a literatura. Utilizou-se do método de triangulação proposto por Thiollent (2007) que consiste em quantificar, qualificar e descrever os dados simultaneamente. Os dados quantitativos foram distribuídos e avaliados por meios de métodos estatísticos em planilha do Excel e estão apresentados em tabelas.

\section{RESULTADOS E DISCUSSÃO}

\section{Caracterização das atividades dos catadores de materiais recicláveis}

A coleta dos resíduos sólidos recicláveis secos é feita pelos empreendimentos diretamente da fonte geradora, tais como residências, condomínios, instituições de ensino básico e superior, comércios, hospitais públicos, órgãos públicos e indústrias.

Para a coleta os empreendimentos dispõem de dois caminhões, um adquirido pelo projeto CATAFORTE, cuja manutenção é responsabilidade dos próprios empreendimentos e outro tipo baú cedido pela prefeitura de Campina Grande, além de diferentes tipos de carrinhos de tração humana, frutos de projetos das instituições de ensino superior e de instituições religiosas. Um dos modelos mais usados é o adaptado à bicicleta, doado pelo governo estadual.

Observou-se que os empreendimentos estão atentos ao mercado da reciclagem e que estão sempre desenvolvendo estratégias para melhorarem as suas receitas. Entre elas, destacam-se o beneficiamento dos materiais recicláveis, como a higienização de latas de ferro e a retirada de rótulos, a prensagem de metais, papel, papelão, plástico, para compactação do volume e o aumento das vendas no peso.

Vale destacar, o uso compartilhado de caminhões para coleta e transporte de resíduos sólidos, com o rateio das despesas de manutenção, e a comercialização de grande parte dos materiais recicláveis recolhida ocorre em rede. Os empreendimentos acordam entre si a venda de materiais recicláveis para os compradores que apresentem melhor preço e que recolham os materiais diretamente de seus galpões. A partir dessas estratégias reduzem sensivelmente as despesas de transporte, e, sobretudo, minimizam a oscilação de preços entre os intermediários (atravessadores e/ou sucateiros).

Desta forma, as estratégias utilizadas pelos catadores de materiais recicláveis, corroboram com o estudo de Alves et al. (2013), os quais destacam que as organizações de redes solidárias têm sido apontadas na literatura como uma ferramenta estratégica para o fortalecimento das associações e cooperativas de catadores de materiais recicláveis. Esse modo de comercialização foi proposto pela Rede Cata PB, uma rede de apoio aos empreendimentos de catadores de materiais recicláveis do estado da Paraíba. 
A Rede cata PB é composta por 13 empreendimentos localizados na zona da mata, agreste e sertão paraibano, tendo como fomentador o Projeto CATAFORTE²- Fortalecimento do Associativismo e Cooperativismo dos Catadores de Materiais Recicláveis, a partir da necessidade de comercializar e garantir melhor agregação de valor aos materiais recicláveis em rede, com o uso compartilhado de caminhões. E como principal articulador, no estado da Paraíba, a Cáritas Brasileira Regional NE³ , representante da Base de Serviços de Apoio à Rede Cata PB. Em 2016, elaborou o Plano de Negócios Sustentáveis, onde a oportunidade definida e construída pelos catadores da Paraíba foi a Comercialização conjunta dos materiais recicláveis (CEADEC, 2016).

Os acompanhamentos das atividades dos empreendimentos mostraram que a Rede Cata PB não foi efetivamente implementada. O que pode ser justificado por uma série de mudanças no cenário político brasileiro, logo, após o impeachment da então presidente, Dilma Rousseff, no ano de 2016. Fato que culminou num processo de desestabilidade de diversas secretarias, entre elas, a Secretaria Nacional de Economia Solidária (SENAES) responsável pela articulação de projetos direcionados a Empreendimentos Econômicos Solidários, nos quais se enquadram associações e cooperativas de catadores de materiais recicláveis. Conforme destaca, Santos (2017) em 2016, a SENAES sofreu rebaixamento para subsecretaria, tendo como principal impacto adverso o corte orçamentário e consequentemente, a descontinuidade de diversos projetos de cunho social, econômico e solidário no Brasil.

Vale ressaltar que a coleta seletiva em Campina Grande, ainda não se encontra totalmente institucionalizada pelo poder público municipal. Ocorre que os empreendimentos de catadores de materiais recicláveis realizam a coleta seletiva no município de forma independente, pois são eles que mantêm o gerenciamento de seus negócios e arcam com suas despesas, inclusive com a renda paga aos seus associados e cooperados, embora, participem de projetos de implementação da coleta seletiva municipal, em escala piloto, como o Recicla Campina ${ }^{4}$, ainda não são renumerados pelo município e aguardam há mais de dois anos a assinatura do contrato de prestação de serviço com a referida prefeitura.

Os catadores de materiais recicláveis e apoiadores da causa ambiental lutam para efetivar a coleta seletiva em Campina Grande, a partir da assinatura do contrato de prestação de serviços entre os empreendimentos e o município. O contrato visa à renumeração da categoria, com intuito de atender às ações relativas ao manejo de resíduos sólidos contidas no Plano Municipal de Gestão de Resíduos Sólidos, aprovado em 2014, e garantir a implementação da coleta seletiva nas quatro zonas geográficas da cidade.

\footnotetext{
${ }^{2}$ CATAFORTE- Negócios Sustentáveis em Redes Solidárias: foi proposto pela Secretaria Geral da União e outros Ministérios em parceria com o Banco do Brasil visando a estruturação de redes de cooperativas e associações de catadores de materiais recicláveis para sua inserção no mercado da reciclagem e a agregação de valor na cadeia de resíduos sólidos.

${ }^{3}$ A Cáritas Brasileira é uma entidade de promoção e atuação social que trabalha na defesa dos direitos humanos, da segurança alimentar e do desenvolvimento sustentável solidário. Foi aprovada pelo edital Comissão de Seleção Pública de Projetos 2014/013 CATAFORTE III - Negócios Sustentáveis em Redes Solidárias.

${ }^{4}$ Recicla Campina é um projeto de coleta seletiva, escapa piloto, gerenciado pela Secretaria de Serviços Urbanos e Meio Ambiente (SESUMA), tendo como participantes cinco empreendimentos de catadores de materiais recicláveis de Campina Grande. Neste projeto, a SESUMA incentiva a adesão de algumas empresas, escolas, residências, comércio, serviços e condomínios, para realizarem a separação e a transferência do material reciclável aos empreendimentos e fornecem o caminhão de coleta. Os catadores de materiais recicláveis, por sua vez, promovem a Educação Ambiental, junto à população, recolhem os resíduos sólidos na fonte geradora, fazem a triagem e comercializam.
} 
Nos empreendimentos $A, C$ e E, a coleta dos resíduos sólidos secos é realizada por homens e mulheres. No entanto, há prevalência de homens na execução da prensagem do material separado e na produção dos fardos, bem como no carregamento destes para o interior do galpão. Atribui-se, principalmente ao maior esforço físico desprendido, durante as atividades. Enquanto, as mulheres realizam, além das atividades de triagem, o desmanche dos materiais e as questões administrativas e organizacionais do empreendimento. Nos Empreendimentos B e D, formados predominantemente por mulheres (100\%), são elas que realizam todas as atividades inerentes à profissão.

Conforme as observações in locu, comumente, os catadores de materiais recicláveis comprometem 50\% de sua carga horária de trabalho (20 horas/média/semanal) para realizar a separação dos materiais recicláveis. A triagem tem como objetivo separar os materiais recicláveis dos materiais não recicláveis (rejeitos). Este processo é realizado manualmente em mesas de triagem, B e C (45\%), diretamente no chão, E (10\%) ou com uso de sacolas e big bags, A e D (45\%). Em todos os empreendimentos (100\%), observou-se que a atividade de triagem dos materiais recicláveis é realizada pelas mulheres, dentro do espaço físico interno do galpão.

De acordo com os dados coletados, foi recolhida pelos empreendimentos de catadores de materiais recicláveis que atuam em Campina Grande-PB, a média mensal de aproximadamente 67 toneladas de materiais recicláveis (Tabela 2). Esses materiais foram reintroduzidos ao mercado da reciclagem, sendo então, destinados de forma correta, seguindo-se o que estabelece a Lei 12.305/2010 (BRASIL, 2010). Na tabela 2, estão descritas as médias mensais e anuais de materiais recicláveis recuperados pelos os empreendimentos.

Tabela 2: Materiais recicláveis recuperados a partir da coleta seletiva realizada pelos empreendimentos de catadores de materiais recicláveis. Campina Grande, estado da Paraíba, Brasil.

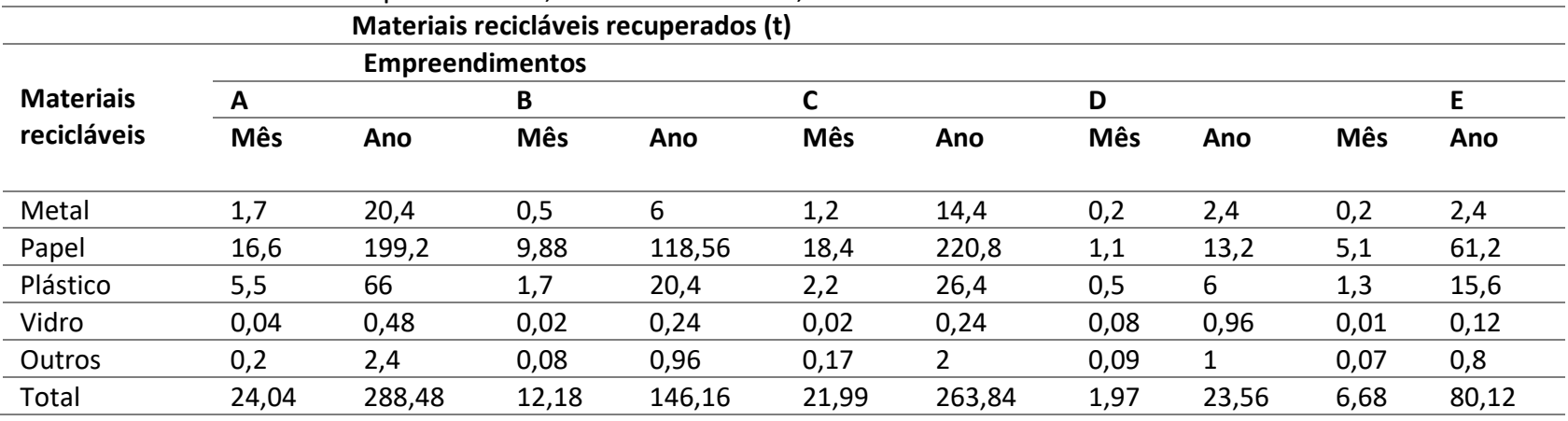

Constatou-se, durante este estudo, uma quantidade expressiva de materiais recicláveis recolhida mensalmente: papel $(51,08 \mathrm{t})$, plástico $(11,2 \mathrm{t})$, metal $(3,8 \mathrm{t})$ vidro $(0,17 \mathrm{t})$ e outros materiais $(0,61 \mathrm{t})$. Ao passo que 802 toneladas de materiais recicláveis foram coletadas no período de um ano. É perceptível a grande contribuição dos catadores de materiais recicláveis para o retorno dos materiais ao mercado da reciclagem, além dos benefícios advindos da coleta e destinação ambientalmente corretas para o meio ambiente local. A participação dos empreendimentos evitou que 802 toneladas de resíduos sólidos fossem aterradas no município de Campina Grande, PB. 
Diversos impactos positivos diretos podem ser destacados, em virtude das atividades dos catadores de materiais recicláveis, sobretudo, a redução do uso da matéria prima virgem, do consumo de água, a economia de energia elétrica e outros insumos. É importante destacar, o decréscimo do ritmo de poluição nos sistemas ambientais.

\section{Reciclagem de materiais do tipo papel/papelão}

Os catadores de materiais recicláveis, associados e cooperados, conseguem retirar de suas coletas, materiais recicláveis que seriam descartados inadequadamente ou dispostos em aterro sanitário. Dentre os materiais recolhidos, o papel é o de maior comercialização (77\%). Contudo, o valor comercial do quilo de papel varia entre $\mathrm{R} \$ \mathbf{0 , 1 5}$ e 0,40 (papel misto e papel branco, respectivamente), caracterizando-se como material de menor relação preço/kg. A média mensal da quantidade de papel recuperada para comercialização é de 51,08 toneladas e aproximadamente 613 toneladas anuais. Comumente, são entregues aos catadores de materiais recicláveis misturados a outros resíduos e sujos, o que restringe a venda e diminui o valor do material no mercado.

O papel/papelão tem o atrativo comercial pelos empreendimentos para sua comercialização, uma vez que constitui material de maior interesse no mercado da reciclagem local pelas empresas aparistas, apesar do baixo preço. Além disso, a produção de papel ocorre praticamente em todas as áreas da sociedade, conferindo maior demanda. De acordo com o relatório 2018-2019 elaborado pela Associação Nacional de Aparistas de Papel - ANAP, em 2018 foram produzidas 10,6 milhões de toneladas de papel no Brasil. Outro fator importante que atrai a coleta do papel/papelão é o seu ciclo de reciclagem que pode ocorrer diversas vezes, exceto aquele destinado para fins sanitários que não pode ser reciclado, tendo apenas um ciclo de vida (ANAP, 2018). A variação de preços no mercado da reciclagem, frequentemente, impossibilita os empreendimentos a comercializarem o papel. Desta forma, foram observados montantes desses materiais, que se acumulam nos galpões, aguardando o aumento do preço, fato que impacta negativamente a renda desses trabalhadores. Periodicamente, esta situação também afeta a venda de outros materiais, como embalagens Tetra Park, latas de leite e garrafas de vidro.

Tabela 3: Quantidade de resíduos de papel/papelão recolhida pelos empreendimentos de catadores de materiais recicláveis. Campina Grande, estado da Paraíba, Brasil.

\begin{tabular}{llcc}
\hline Tipo & Característica & $\begin{array}{c}\text { Recolhida } \\
\text { (média/mês/t) }\end{array}$ & $\begin{array}{c}\text { Percentual } \\
\text { (\%) }\end{array}$ \\
\hline Papel branco & Material de escritório, cadernos, apostilas e livros. & 8,7 & 17 \\
\hline Papel misto & Revistas, folhetos de propagandas, e demais papéis coloridos. & 14,7 & 29 \\
\hline Papelão & Caixas de eletrodomésticos, embalagens em geral. & 27,68 & 51,08 \\
\hline Total & & 54 & 100 \\
\hline
\end{tabular}

A Associação Brasileira de Normas Técnicas- ABNT, por meio da Norma Brasileira Regulamentadora NBR 15483 classifica as aparas de papel e papelão ondulado de acordo com a sua origem em 31 categorias. Resumidamente, as aparas de papel podem ser divididas em quatro grupos básicos: aparas marrons (papéis de embalagens), aparas brancas (papéis destinados a impressão e escrita), aparas de cartão (embalagens de 
remédios, pastas de dentes) e aparas mistas (embalagens de difícil separação) (ABNT, 2009). Os empreendimentos, por sua vez, classificam o papel em três categorias: branco, misto e papelão (Tabela 3).

A maior parcela recolhida é de papelão (54\%), originado de embalagens em geral, seguido de papel misto (29\%), revistas e papéis coloridos e papel branco (17\%), de material de escritório, apostilas e livros.

\section{Reciclagem de plástico}

As embalagens plásticas, comercializadas pelos empreendimentos estudados, são classificadas como Politereftalato de etileno (PET), Polietileno de alta densidade (PEAD), Policloreto de Vinila (PVC) e Polipropileno (PP). Destacam-se em maior quantidade as embalagens de Politereftalato de etileno (PET) provenientes de bebidas (refrigerantes e gaseificados), seguidas de embalagens de água mineral, sucos, produtos químicos, produtos de limpeza pessoal. Os materiais recicláveis do tipo plástico recuperados pelos empreendimentos totalizam a média mensal de 11,2 toneladas (tabela 4).

Tabela 4: Caracterização dos resíduos sólidos do tipo plástico recolhidos pelos empreendimentos de catadores de materiais recicláveis. Campina Grande, estado da Paraíba, Brasil.

\begin{tabular}{|c|c|c|c|}
\hline Tipo & Característica & $\begin{array}{l}\text { Recolhido } \\
\text { (média/mensal/t) }\end{array}$ & $\begin{array}{l}\text { Percentual } \\
\text { (\%) }\end{array}$ \\
\hline PEAD branco & $\begin{array}{l}\text { Polietileno de alta densidade: recipientes de iogurte, produtos de } \\
\text { limpeza (amaciante, sabão líquido, água sanitária). }\end{array}$ & 1,4 & 12 \\
\hline PEAD colorido & $\begin{array}{l}\text { Polietileno de alta densidade: recipiente coloridos de produtos de } \\
\text { limpeza descritos anteriormente. }\end{array}$ & 0,6 & 5 \\
\hline PET & Recipientes de Politereftalato de etileno transparentes. & 2,4 & 21 \\
\hline $\begin{array}{l}\text { Plástico bacia } \\
\text { branca }\end{array}$ & $\begin{array}{l}\text { Recipientes de Politereftalato de etileno colorido (garrafas de suco, } \\
\text { refrigerante, produtos de limpeza pessoal). }\end{array}$ & 0,8 & 7 \\
\hline $\begin{array}{l}\text { Plástico bacia } \\
\text { colorida }\end{array}$ & $\begin{array}{l}\text { Recipientes de Polipropileno brancos: manteiga, iogurte, coalhada, } \\
\text { potes de sorvete, etc. }\end{array}$ & 0,9 & 8 \\
\hline Plástico cadeira & $\begin{array}{l}\text { Recipientes de Polipropileno coloridos, tampas, achocolatado, potes } \\
\text { de doce de leite. }\end{array}$ & 0,2 & 2 \\
\hline Plástico Carina & Emborrachados de calçados, correias, mangueiras, brinquedos, etc. & 0,3 & 3 \\
\hline Plástico fino & Embalagens transparentes. & 2,4 & 22 \\
\hline Plástico sacola & Cadeiras de plástico, baldes de água mineral, plásticos de Poliestireno. & 0,9 & 8 \\
\hline PVC & Embalagens com pigmentação. & 0,7 & 7 \\
\hline Soro & Canos de construção. & 0,6 & 5 \\
\hline Total & & 11,2 & 100 \\
\hline
\end{tabular}

De acordo com o PMGRS (Plano Municipal de Gestão Integrada de Resíduos Sólidos de Campina Grande), publicado em 2014 por meio da Lei Complementar 087/2014, Campina Grande apresenta em sua composição gravimétrica, o plástico como resíduo sólido de maior produção no perímetro urbano (22,25\%). No contexto nacional, Besen et al. (2011) descrevem que dos resíduos descartados no Brasil, 57,41\% são orgânicos, $16,49 \%$ plástico, $13,16 \%$ de papel e papelão, $2,34 \%$ de vidro, $1,56 \%$ de material ferroso, $0,51 \%$ de alumínio, $0,46 \%$ de inertes e $8,1 \%$ de outros materiais.

As embalagens de PET apresentam maior valor comercial entre os recicláveis de plástico, o quilo varia de $\mathrm{R} \$ 1,20$ a $\mathrm{R} \$ 1,30$. Os empreendimentos para melhorarem a renda de seus associados, realizam a separação de resíduos plásticos conforme o interesse do comprador, considerando a pigmentação das embalagens, geralmente os transparentes ou 'brancas', sobressaem em relação às pigmentadas. Os empreendimentos que possuem prensas hidráulicas, A, B, C, D (80\%) realizam a prensagem e o enfadamento 
de algumas embalagens de plástico. Desta forma, além de agregar valor comercial ao material plástico, reduzem a ocupação do espaço interno do galpão e os riscos de desmoronamentos.

Nos empreendimentos A, B, C, D, E, observou-se, durante a atividade de triagem, a presença de materiais orgânicos (resto de comidas, cascas de frutas) e sanitários (papel higiênico, fraldas descartáveis e absorventes), e outros materiais não recicláveis como madeira, embalagens de isopor e tecidos, todos classificados como rejeitos. Ademais, a presença de materiais perfuro cortantes, como latas de ferro, e vidro. Desta forma, corroborando com os estudos de Santos (2016) e Batista et al. (2014) que identificaram durante a separação dos resíduos sólidos a presença de riscos químico, biológico, ergonômico e de acidente. Porquanto a separação dos resíduos sólidos não ocorre de forma correta e os catadores de materiais recicláveis ficam submetidos a vários riscos. Quando misturados, os riscos de contaminação por organismos patogênicos são potencializados, a exemplo de vírus, bactérias e helmintos na fase de ovo. Principalmente, devido a manipulação de materiais não higienizados.

A pandemia declarada pela Organização Nacional de Saúde, no dia 11 de março de 2020, em decorrência do novo coronavírus, SARS - CoV 2019 - 2, revelou um desafio mundial, no manejo de resíduos sólidos, devido, principalmente, ao potencial de disseminação e letalidade da doença Covid-19 e o risco de contaminação dos profissionais da coleta seletiva com os materiais infectados. Sendo assim, mediante a gravidade da pandemia, diversos estados brasileiros, entre eles, os do Distrito Federal e de São Paulo, suspenderam a coleta seletiva e a triagem de resíduos sólidos (ADASA, 2020), em outros municípios, a exemplo de Campina Grande/PB, persiste a coleta seletiva, todavia, não há a triagem.

Os materiais recolhidos ficam em quarentena, observando-se o tempo de vida desse vírus nos resíduos sólidos. Em Campina Grande, por decisão dos cooperados e associados, a coleta referente ao Projeto Recicla Campina foi parcialmente interrompida, apenas dois empreendimentos ( $B, C$ e E) suspenderam, principalmente por falta de assistência por parte da prefeitura e por reconhecerem os riscos que estão submetidos. Em alguns setores, há coleta esporádica de material reciclável por todos os empreendimentos (condomínio e comércio), mas o material, no entanto, fica em quarentena, sendo triado depois de oito dias da coleta.

O Movimento Nacional de Catadores de Materiais Recicláveis (MNCMR), também se posicionou sobre os riscos de coletar resíduos sólidos no período da pandemia do Covid-19, alertando os catadores de materiais recicláveis sobre a importância de suspender a coleta seletiva e redobrar os cuidados com o uso de Equipamentos de Proteção Individual: máscaras, luvas, capas e botas, assim como reforçar as medidas de higienização com álcool 70\%. A Associação Brasileira de Engenharia Sanitária e Ambiental emitiu um relatório técnico sobre os a capacidade de sobrevivência do vírus SARS - CoV 2019 - 2, na superfície dos resíduos sólidos conforme Kampf et al. (2020), o vírus pode permanecer por horas e até dias, no alumínio (2-8 horas), madeira e vidro (4 dias), papel (4-5 dias) e plástico (5 dias).

Nesse contexto, é necessário, exigir medidas profiláticas e remediadoras, por parte do poder público, que visem melhorar as condições de trabalho e higiene, entre elas, o fornecimento de EPIs, orientações para os trabalhadores de como agirem frente à problemática, orientações à população de como descartar os seus 
resíduos sólidos, sobretudo, em residências de pessoas diagnosticadas com Covid- 19. Ademais, o poder público deve garantir renda aos catadores de materiais recicláveis, durante a paralisação da coleta dos resíduos sólidos, por se tratar do meio de sobrevivência da categoria. Visto que os efeitos da doença têm provocado inúmeras mortes em todo globo terrestre. Espera-se, urgentemente, o posicionamento da gestão pública, em diversos municípios brasileiros.

Diante deste cenário é fundamental promover ações educativas para sensibilizar a população, motivando-a sobre a importância de segregar resíduos sólidos. Promover a higienização dos resíduos sólidos recicláveis secos, bem como, acondicionar os materiais em sacos duplos e limpos, resistentes e descartáveis, para melhorar a qualidade sanitária dos materiais recicláveis, a fim de reduzir implicações sobre a saúde dos trabalhadores que manejam os resíduos sólidos.

As embalagens plásticas são constituídas de polímero sintético, a matéria prima é originada de combustíveis fósseis, como petróleo, gás e carvão. Vasconcelos (2019) destaca que o consumo de plásticos sofreu crescimento vertiginoso influenciado pelo estilo de vida urbano, principalmente pelo aumento na produção de embalagens alimentícias, usadas para aumentar a vida útil dos produtos industrializados. Essas embalagens possibilitaram o descarte de materiais de uso pessoal, evitando, principalmente contaminação biológica. No entanto, milhares de materiais plásticos, como sacolas, canudos e garrafas são lançados na natureza indiscriminadamente, agravando os problemas de cunho ambiental.

De acordo com Geyer et al. (2017) estima-se que 8300 milhões de toneladas métricas de plásticos virgens foram produzidas até o momento no mundo. Em 2015, foram geradas aproximadamente 6.300 toneladas métricas de resíduos plásticos, dos quais $9 \%$ foram reciclados, $12 \%$ foram incinerados e $79 \%$ foram acumulados em aterros sanitários ou no ambiente natural.

O descarte impróprio do plástico na natureza gera uma série de prejuízos ambientais, econômicos e sociais. Os impactos negativos estão relacionados à vida útil curta e o tempo longo de degradação. O que pode demorar de 100 a 400 anos para ser totalmente decomposto (VASCONCELOS, 2019). Outras problemáticas são provocadas pelo acumulo desses resíduos nas ruas, como a poluição visual, o aumento de vetores de doenças, a ineficiência na drenagem de águas pluviais, consequentemente, o entupimento de vias públicas que provocam alagamentos. Além disso, tem sido observada a interferência dos resíduos plásticos nas cadeias alimentares oceânicas, fato que tem promovido a morte de diversas espécies marinhas.

Outro ponto que influência negativamente é o espaço ocupado pelos montantes enviados aos aterros sanitários, o que dificultam a compactação e a degradação de materiais biodegradáveis. Atualmente, os descartáveis (fraudas, canudos, copos) estão entre os materiais que fazem parte da vida moderna e que carecem de atenção especial para redução do consumo. Conforme tabela 4, fraudas descartáveis e materiais inertes representam $8,69 \%$ do resíduo sólido urbano da cidade, uma parcela considerável quando comparada aos impactos negativos que promove na natureza.

Pensando em reverter os impactos negativos advindos do descarte do plástico, alguns estados brasileiros, proibiram a comercialização de sacolas e canudos, esta medida pode evitar que muitos resíduos desta origem, sejam descartados no meio ambiente. Contudo, a medida ainda não é suficiente para resolver 
os problemas relacionados ao descarte de plásticos. Uma vez que não educa a sociedade a consumir conscientemente tão pouco sensibiliza as pessoas nem os estabelecimentos a separarem seus resíduos sólidos para a reciclagem (PLASTIVIDA, 2019).

\section{Reciclagem de metal}

A média de recolhimento do material metal é 3,84 toneladas/mês, como mostra a tabela 5 . Dentre os metais recolhidos pelos empreendimentos, destacam-se alumínio (23\%), ferragens (58\%) e cobre (1\%). 0 alumínio do tipo latinhas (0,5 t/mês) é um dos materiais mais comercializados pelos empreendimentos, ficando atrás apenas das ferragens (2,2 t/mês). O alumínio chaparia (0,32 t/mês), também classificado como alumínio duro, constituiu-se de peças rígidas, principalmente embalagens de aerossóis.

Tabela 5: Caracterização dos resíduos sólidos do tipo metal recolhidos pelos empreendimentos de catadores de materiais recicláveis. Campina Grande, estado da Paraíba, Brasil.

\begin{tabular}{llll}
\hline Tipo & Característica & $\begin{array}{l}\text { Recolhido } \\
\text { (média/mensal/t) }\end{array}$ & $\begin{array}{l}\text { Percentual } \\
\text { (\%) }\end{array}$ \\
\hline $\begin{array}{l}\text { Alumínio } \\
\text { chaparia }\end{array}$ & $\begin{array}{l}\text { Peças rígidas de alumínio (chaparias, grades, recipiente de } \\
\text { aerossol) }\end{array}$ & 0,32 & 8 \\
\hline Alumínio duro & Peças de eletrodomésticos (ferro, base de fogão) & 0,04 & 1 \\
\hline Alumínio latinha & Latinha de bebidas & 0,5 & 13 \\
\hline Alumínio panela & Panelas diversas & 0,03 & 1 \\
\hline Bateria & Baterias de automóveis & 0,02 & 0,7 \\
\hline Cobre & Retirado de bobinados de eletrodomésticos & 0,04 & 1 \\
\hline Ferragens & Diversas origens (cadeira, fogão, geladeira, grades) & 2,23 & 58 \\
\hline Metal & Metal fino & 0,03 & 1 \\
\hline Motor & Motor de geladeira, freezer & 0,01 & 0,3 \\
\hline Outros materiais & Latas de leite e suplementos & 0,62 & 16 \\
\hline Total & & 3,84 & 100 \\
\hline
\end{tabular}

A reciclagem do alumínio, tem se fortalecido mundialmente como atividade economicamente viável e sustentável. Em geral, o material pode ser reciclado diversas vezes sem perder suas propriedades. As latinhas de bebidas industrializadas, destacam-se no mercado da reciclagem devido, principalmente, ao seu ciclo de vida curto e ao elevado consumo da população. Segundo dados da ABAL (Associação Brasileira de Alumínio) em 2015, o Brasil reciclou 602 mil toneladas de alumínio. Desse total, 292,5 mil toneladas referem-se às latinhas de alumínio para bebidas, o que corresponde a 97,9\% do total de embalagens consumidas em 2015, índice que mantém o Brasil entre os países líderes em reciclagem de latinhas desde 2001. Todavia, é importante destacar que este dado se refere apenas ao alumínio de origem de bebidas industriais, desconsiderando outros materiais da mesma natureza.

Conforme destacam Ribeiro et al. (2014) é necessário um aprofundamento do conhecimento sobre o mercado de reciclagem de alumínio no Brasil e em seus diversos mercados regionais/locais, considerando o conjunto total de sucatas e não somente ponderando o segmento "latas de alumínio" para elevar a taxa de recuperação desse material, que pode facilmente superar os referidos $35,2 \%$ no nível nacional. Vale ressaltar que no ano de 2015 , somente a etapa da coleta de latas de alumínio para bebidas (latas usadas) injetou R\$ 730 milhões diretamente na economia brasileira (CEMPRE, 2016). O alumínio latinha foi comercializado pelos 
empreendimentos no valor de $\mathrm{R} \$ 3,50$, sendo este, o único material que manteve estável o preço de comercialização, durante todo período estudado.

O material mais valorizado economicamente entre os metais, é o cobre, comercializado no mercado da reciclagem local no valor de $\mathrm{R} \$ 18,00 / \mathrm{kg}$. Observou-se a comercialização de cerca de $41 \mathrm{~kg} / \mathrm{mês}$ deste metal, quantidade recolhida pelos cinco empreendimentos, o que representou em termos monetário, o equivalente a $R \$ 738,00$.

O cobre é componente de peças de eletrodomésticos que são desmanchadas pelos catadores de materiais reciclável, a fim de retirá-lo para a venda. Nos empreendimentos de catadores de materiais recicláveis estudados, o processo de desmanche é realizado manualmente, demandando tempo e equipamentos para realização da atividade. Quando comparado a outros metais, a forma de obtenção do cobre requer maior desprendimento de tempo para sua separação e caracteriza-se como atividade que aumentam os riscos químico, físico e de acidente.

A precariedade das ferramentas e a ausência de equipamentos de proteção individual, como luvas, máscaras e óculos, submetem os trabalhadores a riscos de cortes e perfurações, além da possibilidade de contaminação por metais pesados. Os riscos observados durante o processo de desmanche de bobinado de cobre, extraído de eletrodomésticos (ventilador, televisão), comprometem a segurança dos catadores de materiais recicláveis na realização de suas atividades, principalmente, devido ao manejo de resíduos com metais pesados (CAVALCANTE, 2018; SILVA, 2019; SANTOS, 2016; BATISTA et al., 2014; SILVA et al., 2012; RIBEIRO et al., 2014).

\section{Reciclagem de vidro}

O vidro é o material que pode ser totalmente e inúmeras vezes reciclado. Sua característica inerte, torna sua reciclagem uma atividade sustentável do ponto de vista, econômico, social e ambiental. Comparado a outros materiais recicláveis, a recuperação do vidro, pelos empreendimentos, é menor, decorrente do mercado da reciclagem local.

A média de recuperação do vidro é 0,17 toneladas mês (tabela 1). Na composição gravimétrica dos resíduos sólidos produzidos em Campina Grande, o vidro representa 2,24\% (PMGIRES,2014). Nos empreendimentos estudados, a separação do vidro ocorre por processos manuais, no qual o vidro de interesse comercial, a maior parte garrafas, é separado dos demais recicláveis que não possuem valor comercial. Entre os resíduos sólidos de vidro de interesse comercial, predominam as garrafas transparentes, que armazenam bebidas alcoólicas. O valor destes recicláveis está entre $\mathrm{R} \$ \mathbf{0 , 1 5}$ a 0,40 centavos/unidade, conforme o tamanho da garrafa.

O vidro presente na coleta seletiva é classificado como vidro doméstico, de acordo com a AMBIVIDRO (2009) são garrafas, potes, frascos, tigelas, travessas, copos, pratos e outros vasilhames fabricados em vidro comum nas cores branca, âmbar verde e azul. Dados do CEMPRE (2012) apontam que os cacos encaminhados para reciclagem não podem conter pedaços de cristais, espelhos, lâmpadas e vidro plano usado nos automóveis e na construção civil. Por terem composição química diferente, esses tipos de vidro 
causam trincas e defeitos nas embalagens. No entanto, algumas indústrias de vidro já incorporam percentuais de vidro plano na produção. As principais garrafas comercializadas nos empreendimentos encontram-se na tabela 6.

Tabela 6: Caracterização dos resíduos sólidos do tipo vidro recolhido pelos empreendimentos de catadores de materiais recicláveis. Campina Grande, estado da Paraíba, Brasil.

\begin{tabular}{llll}
\hline Tipo & Característica & Recolhido (média/unidade) & Peso seco (kg) \\
\hline & Cachaça Matuta (1l) & 137 & 68,91 \\
\cline { 2 - 3 } Vidro/garrafa & Cachaça Matuta $(275 \mathrm{ml})$ & 77 & 13,86 \\
\cline { 2 - 3 } & Vodka Paloff $(1 \mathrm{l})$ & 112 & 52,19 \\
\cline { 2 - 3 } & Conhaque Drehe $(900 \mathrm{ml})$ & 107 & 44,72 \\
\hline Total & & 433 \\
\hline
\end{tabular}

A ausência de empresas recicladoras de vidro, no estado da Paraíba, pode ser apontada como um dos fatores que justificam esse percentual. Desta forma, não há comercialização de diversas embalagens de vidro que chegam aos empreendimentos pela coleta seletiva. Outra justificativa é o interesse comercial das empresas recicladoras em vidros planos. Conforme o Relatório Anual do Setor Produtivo (2015) o parque industrial de produção de vidro brasileiro está concentrado em quatro grandes empresas, na região sudeste, sendo os vidros planos o produto de interesse comercial para utilização na construção civil.

O empreendimento $D$, coleta, separa e processa o vidro, visto que, detém equipamentos (trituradores, estufas) para realizar a atividade. A partir do beneficiamento são confeccionadas peças artesanais para serem comercializadas, com o intuito de melhorar a renda das catadoras de materiais recicláveis, além de reduzir o número de garrafas do meio ambiente.

A Política Nacional de Resíduos Sólidos descreve prioritariamente a não geração, redução, reutilização, reciclagem e tratamento dos resíduos sólidos, bem como disposição final ambientalmente adequada dos rejeitos (BRASIL, 2010). A redução do descarte de vidro é essencial para mitigar impactos negativos diretos e indiretos do seu descarte sobre o meio ambiente e sociedade, uma vez que sua decomposição total pode levar até 10 mil anos. A reutilização e a reciclagem do vidro diminuem a pressão sobre os recursos naturais, economizam matéria prima, água e poupam energia. Para cada $10 \%$ de cacos de vidro (reciclados e triturados) na mistura com a matéria prima mineral virgem, economizam-se 3 a $4 \%$ da energia necessária para a fusão nos fornos industriais e reduzem-se em 10\% a utilização de água (CEMPRE, 2012).

\section{Recursos naturais poupados a partir da reciclagem}

Na tabela 7 são enumerados os recursos naturais poupados com a reciclagem dos materiais: alumínio, papel e plástico, recuperados pelos empreendimentos de catadores de materiais recicláveis no período de 12 meses. Tomando como base a média anual de recolhimento do alumínio (10,7 t); papel (613 t); plástico $(134,4)$, e os custos municipais que foram poupados com coleta e aterramento dos resíduos sólidos recuperados (802 t), foram calculados com o preço de $R \$ 94,10 / t$ para a coleta e $R \$ 32,98 / t$ para o aterramento (SANTOS, 2016). 
Tabela 7: Recursos naturais e financeiros poupados com a reciclagem dos materiais recicláveis (alumínio, papel e plástico) em um ano de recolhimento. Campina Grande, estado da Paraíba, Brasil.

\begin{tabular}{ll} 
Recursos naturais Poupados & Quantidade \\
\hline Energia (Mw) & $3.033,33$ \\
\hline Bauxita (ton.) & 53,5 \\
\hline Água (m ${ }^{3}$ ) & $58.872,52$ \\
\hline Árvore (unidade) & 18,3 \\
\hline Petróleo (barril) & $5.529,22$ \\
\hline Custos municipais com coleta e aterramento (R\$) & $101.918,16$
\end{tabular}

Observou-se a economia de 3.033,33 Megawatts de energia elétrica, a partir da reciclagem de alumínio, papel e plástico. Na produção de papel economizou-se $58.872,52 \mathrm{~m}^{3}$ de água, enquanto a quantidade de árvores poupada foi de 18,3 unidades. Identificou-se a redução de 53,5 toneladas de bauxita que deixaram de ser extraídas para produção do alumínio e a redução de 5.529,22 barris de petróleo na produção do papel e plástico.

Os resultados obtidos ratificam que a atuação dos empreendimentos de catadores de materiais recicláveis ressignificam o ciclo de produção e descarte de resíduos sólidos. Consequentemente, apontam a prestação de serviço ambiental que reduz impactos negativos oriundos da extração da matéria prima virgem, e da utilização de água e energia. Outros impactos prováveis podem ser citados, como: a redução do desmatamento, da poluição oriunda da refinaria do petróleo, e o decréscimo no lançamento de gases de efeito estufa na atmosfera.

Outro impacto positivo observado com a atuação dos empreendimentos foi a redução da receita municipal que a prefeitura, outrora, aplicaria caso esses materiais não fossem coletados pelos catadores de materiais recicláveis, $\mathrm{R} \$ \mathbf{1 0 1 . 9 1 8 , 1 6}$ Além das despesas com a coleta de resíduos sólidos, sabe-se que as despesas decorrentes dos impactos do aterramento, também foram reduzidas.

A reciclagem reduz significativamente os impactos negativos diretos e indiretos nos sistemas ambientais, entre eles, a diminuição do lançamento de resíduos poluentes na atmosfera, como os gases estufas, principalmente o dióxido de carbono. Uma vez que poupam a extração e o beneficiamento da matéria prima (CHAVES et al., 2017).

Os benefícios ambientais da reciclagem observados nesse trabalho, corroboram com os estudos de Chaves et al. (2017) e Ribeiro et al. (2014), os quais concluíram que os ganhos econômicos de controle ambiental decorrem do fato de que a produção a partir de matéria prima virgem normalmente provocar um grau de poluição da água, do ar e do solo, muito maior do que a produção a partir de materiais reciclados (CHAVES et al., 2017).

Apesar da coleta seletiva realizada pelos empreendimentos de catadores de materiais recicláveis ser responsável direta pelos impactos positivos descritos, a renda mensal registrada durante o período estudado foi inferior ao salário nacional vigente. A média mensal de $\mathrm{R} \$ 482,74$, comumente completada com atividades extras e auxílios sociais não é suficiente à inclusão socioeconômica da categoria.

Desde a década de 1990, diversos atores sociais, como MNCR (Movimento Nacional de Catadores de Materiais Recicláveis), universidades, pesquisadores e ONG's, promovem os encontros voltados a discutir a inclusão socioeconômica, dessa categoria, buscam, sobretudo, que os órgãos públicos reconheçam a 
atividade ambiental que o catador de materiais recicláveis desempenha nos municípios, a partir da renumeração digna e do trabalho decente.

Os empreendimentos de catadores de materiais recicláveis estudados, não são renumerados pela coleta seletiva que realizam na cidade, tampouco pelo serviço ambiental que prestam a sociedade. Desta forma, apenas a comercialização dos materiais recicláveis, torna-se insuficiente para obtenção de renda compatível com o salário nacional, uma vez que a maior parte da população, não destina corretamente seus resíduos sólidos, e a comercialização não acontece diretamente à indústria - a figura do atravessador ainda é uma realidade -, dificultando a atuação dos empreendimentos. Ademais, deve ser acrescentado o serviço de educação ambiental que realizam ao sensibilizarem a população sobre a coleta seletiva, despertando os munícipes adotarem posturas de preservação e conservação do ambiente e assim, garantir os seus direitos trabalhistas (Previdência social, férias, licença maternidade, auxilio doença).

\section{CONCLUSÕES}

De acordo com os resultados obtidos neste trabalho, a atuação dos empreendimentos de catadores de materiais recicláveis em Campina Grande, estado da Paraíba, Brasil, ressignificam o ciclo de produção e o descarte de resíduos sólidos. Logo, ratificam que o exercício profissional desses catadores, compreende prestação de serviços ambientais que reduz significativamente, dentre outros, os impactos negativos devido a extração da matéria prima virgem e da utilização de água e energia. A atuação desses empreendimentos proporcionou no período estudado a recuperação de 802 t de materiais recicláveis. Esses materiais foram reintroduzidos na indústria da reciclagem e evitaram impactos negativos da extração, transporte e beneficiamento da matéria prima, bem como os decorrentes do descarte inadequado dos mesmos no meio ambiente.

Foram identificados vários benefícios ambientais, econômicos e sociais provocados pelos catadores de materiais recicláveis, porém, a categoria não possui renda compatível com o salário nacional. A renda média mensal foi de $\mathrm{R} \$ 482,74$. Renda que não os garante usufruir de direitos trabalhistas. $\mathrm{O}$ enfrentamento cotidiano com as carências de infraestrutura e equipamento para execução das atividades, somada à ausência de separação dos resíduos sólidos na fonte geradora e à falta de reconhecimento do seu papel para o meio ambiente e sociedade, influenciam diretamente nas condições indignas de trabalho e de vida e afetam a saúde emocional desses trabalhadores. A inclusão socioeconômica dos catadores de materiais recicláveis por meio de pagamento pelos serviços ambientais e educacionais prestados é essencial à reversão das condições precárias de trabalho e à garantia de vida digna.

\section{REFERÊNCIAS}

ABAL. Associação Brasileira de Alumínio. Reciclagem do alumínio. São Paulo: ABAL, 2018.

ABRAMOVAY, R.; ESPERANZA J. S.; PETITGAND, C.. Lixo zero: gestão de resíduos sólidos para uma sociedade mais próspera. São Paulo: Instituto Ethos, 2013.
ADASA. Agência Reguladora de Águas, Energia e Saneamento Básico do Distrito Federal. Nota Técnica N. 4/2020: ADASA/SRS/CORR. Brasília: ADASA, 2020.

ALVES, J. C. M.; MEIRELES, M. E.. Gestão de resíduos: as possibilidades de construção de uma rede solidária entre associações de catadores de materiais recicláveis. Revista 
Eletrônica Sistemas \& Gestão, v.8, n.2, p.160-170, 2013. DOI: http://10.7177/sg.2013.v8.n2.a5

ANAP. Associação Nacional de Aparistas de Papel. Relatório anual. São Paulo: ANAP, 2018.

ABNT. Associação Brasileira de Normas Técnicas. NBR 15483: Classificação das aparas de papel e papelão. Rio de Janeiro: ABNT, 2004.

BARDIN, L.. Análise de Conteúdo. 5 ed. Lisboa: 70, 2009.

BESEN, G. R.. Coleta seletiva com inclusão de catadores: construção participativa de indicadores e índices de sustentabilidade. Tese (Doutorado) - Faculdade de Saúde Pública, São Paulo, 2011.

BRASIL. Lei n.12.305. Dispõe sobre a Política Nacional de Resíduos Sólidos. Brasília: DOU, 2010.

CASTILHO JUNIOR, A. B.; RAMOS, N. F.; ALVES, C. M.; FORCELLINI, F. A.; GRACIOLLI, O. D.. Catadores de materiais recicláveis: análise das condições de trabalho e infraestrutura operacional no Sul, Sudeste e Nordeste do Brasil. Ciência de saúde coletiva, Rio de Janeiro, v.18, n.1, 2013.

CAVALCANTE, L. P. S.. Gestão integrada de resíduos sólidos e riscos que estão expostos catadores de materiais recicláveis. Tese (Doutorado em Recursos Naturais), Programa de Pós-graduação em Recursos Naturais, Centro de Tecnologia e Recursos Naturais, Universidade Federal de Campina Grande - Paraíba - Brasil, 2018.

CEMPRE. Compromisso Empresarial para a Reciclagem. Ficha técnica: Vidro. CEMPRE: São Paulo, 2012.

CEMPRE. Compromisso Empresarial para a Reciclagem. Ficha técnica: Latas de Aço. CEMPRE: São Paulo. 2016.

CHAVES, C. A.; MARQUES, S. A.; SILVA, W. S. S.. Benefícios da Reciclagem de Materiais: o caso do alumínio. Revista Livre de Sustentabilidade e Empreendedorismo, Curitiba, v.3, n.3, p.111-134, 2017.

COUTINHO, M. C. M.. Programa de Coleta Seletiva Solidária na Universidade Federal de Campina Grande. Dissertação (Mestrado em Gestão de Políticas Públicas e Avaliação da Educação Superior) - Universidade Federal da Paraíba, João Pessoa, 2017.

GEYER, R.; JAMBECK, J. R.; LAW, K. L.. Production, use, and fate of all plastics ever made. Science Advances, v.3, n7, 2017. DOI: http://10.1126/sciadv.1700782

IBGE. Instituto Brasileiro de Geografia e Estatística. Censo Demográfico. Brasília: IBGE, 2010.

IBGE. Instituto Brasileiro de Geografia e Estatística. Estimativa Estatística. Brasília: IBGE, 2017.

KAMPF, G.; TODT, D.; PAFSENDER, S.; STEINMANN, E.. Persistence of cornaviruses on inanimate surfaces anda their inactivation with biocidal agens. Journal of Hospital Infection, v.104, p.246-251, 2020.
KUHN, N.; BOTELHO, L. L. R.; ALVES, A. A. A.. A coleta seletiva à luz da PNRS nos estados brasileiros: uma revisão sistemática integrativa. Revista Brasileira de Planejamento e Desenvolvimento, Curitiba, v.7, n.5, 2018.

MMA. Ministério do Meio Ambiente. CATAFORTE: Fortalecimento do Associativismo e do Cooperativismo dos Catadores de Materiais Recicláveis. Brasília: MMA, 2017.

PLASTIVIDA. Instituto Socioambiental de Plásticos. Posicionamento sobre o banimento de plásticos de uso único ou descartáveis. São Paulo: PLASTIVIDA, 2019.

REICHERT, G. A.; MENDES, C. A. B.. Avaliação do ciclo de vida e apoio à decisão em gerenciamento integrado e sustentável de resíduos sólidos urbanos. Engenharia Sanitária e Ambiental, v.19, n.3, 2014

RIBEIRO, L. A.; SILVA, M. M. P.; CAVALCANTE, L. P. S. NASCIMENTO, J. M.. Análise de tecnologias para coleta, transporte e triagem de resíduos sólidos em uma associação de Catadores de Materiais Recicláveis, Campina Grande-PB. In: CONGRESSO BRASILEIRO DE ENGENHARIA SANITÁRIA E AMBIENTAL, 5. Anais. Belo Horizonte, 2014.

RIBEIRO, L. C. S.; FREITAS, L. F. S.; CARVALHO, J. T. A.; OLIVEIRA FILHO, J. D.. Aspectos econômicos e ambientais da reciclagem: um estudo exploratório nas cooperativas de catadores de material reciclável do Estado do Rio de Janeiro. Revista Nova Economia, Belo Horizonte, v.24, n.1, 2014.

SANTOS, B. D.. Alternativas mitigadoras de riscos ocupacionais no exercício profissional de catadores de materiais recicláveis vinculados a ARENSA, Campina Grande-PB. Dissertação (Mestrado em Ciência e Tecnologia Ambiental) - Universidade Estadual da Paraíba, Campina Grande, 2016.

SANTOS, T. F. R.. Reflexões sobre as Políticas Públicas voltadas aos (às) Catadores (as) de Materiais Recicláveis no Estado da Paraíba: entre as diretrizes nacionais e a implementação local. Revista Brasileira de Políticas Públicas e Internacionais, João Pessoa, v.3, n.1, p. 206-229, 2017.

SANTOS, B. D.; SILVA, M. M. P.; COSTA, M. P.; CAVALCANTE, L. P. S.. Equipamentos de Proteção Individual para catadores de resíduos sólidos associados em Campina Grande-PB. In: SIMPÓSIO INTERNACIONAL DE GERENCIAMENTO DE RESÍDUOS SÓLIDOS EM UNIVERSIDADES. Anais. Campina Grande, 2017a.

SANTOS, B. D.; SILVA, M. M. P.; COSTA, M. P. COSTA, E. S. Condições de Infraestrutura e de Trabalho de Catadores de Materiais Recicláveis. In: SIMPÓSIO INTERNACIONAL DE GERENCIAMENTO DE RESÍDUOS SÓLIDOS EM UNIVERSIDADES. Anais. Campina Grande, 2017b.

SILVA, M. M. P.; TAVARES, J. S.; OVRUSKI, B. S. C.; FEITOSA, W. B. S.; LEITE, V. D.. Avaliação sanitária de resíduos sólidos orgânicos domiciliares em municípios do semiárido paraibano. Revista Caatinga, Mossoró, v.23, n.2, p.87-92, 2010.

SILVA, M. M. P.; RIBEIRO, L. A.; CAVALCANTE, L. P. S.; OLIVEIRA, A. G.; SOUZA, R. T. M.; OLIVEIRA, J. T.. Quando educação ambiental faz diferença, vidas são transformadas. Revista Eletrônica de Mestrado em Educação Ambiental, v.28, 2012. 
SILVA, M. M. P.; SOARES, E. S.; SOUZA, M. V.; RIBEIRO, L. A.; SANTOS, B. D.. Inovações Tecnológicas para prevenção de riscos que estão submetidos os catadores de materiais recicláveis que atuam em Campina Grande-PB. In: CONGRESSO BRASILEIRO DE ENGENHARIA SANITÁRIA E AMBIENTAL, 30. Anais. São Paulo: ABES, 2019.

SILVA, M. M. P.. Manual de educação ambiental: uma contribuição à formação de agentes multiplicadores em educação ambiental. Curitiba: Appris, 2020.
SOUZA, M. F. B.; SILVA, M. A. L.; MORAIS, S. R. A.; MORAIS, C. R. S. A tecnologia social na reciclagem de vidro: o caso da associação de catadores e recicladores do município de Campina Grande. In: CONGRESSO DE ENGENHARIA SANITÁRIA E AMBIENTAL, 28. Anais. São Paulo: ABES, 2015.

THIOLLENT, M.. Metodologia da pesquisa-ação. 15 ed. São Paulo: Cortez, 2007.

VASCONCELOS, Y.. Planeta Plástico: Ambiente Sustentabilidade e Tecnologia. Revista Pesquisa FAPESP, 2019.

A CBPC - Companhia Brasileira de Produção Científica (CNPJ: 11.221.422/0001-03) detém os direitos materiais desta publicação. Os direitos referem-se à publicação do trabalho em qualquer parte do mundo, incluindo os direitos às renovações, expansões e disseminações da contribuição, bem como outros direitos subsidiários. Todos os trabalhos publicados eletronicamente poderão posteriormente ser publicados em coletâneas impressas sob coordenação da Sustenere Publishing, da Companhia Brasileira de Produção Científica e seus parceiros autorizados. Os (as) autores (as) preservam os direitos autorais, mas não têm permissão para a publicação da contribuição em outro meio, impresso ou digital, em português ou em tradução. 